\title{
Polimorfismo no padrão de manchas tegumentares de larvas e adultos de Ceraeochrysa caligata (Neuroptera: Chrysopidae) e redescrição dos instares larvais
}

\author{
Gustavo G. Viana \& Gilberto S. Albuquerque
}

\begin{abstract}
Laboratório de Entomologia e Fitopatologia, Centro de Ciências e Tecnologias Agropecuárias, Universidade Estadual do Norte Fluminense Darcy Ribeiro. Avenida Alberto Lamego 2000, 28013-602 Campos dos Goytacazes, Rio de Janeiro, Brasil. E-mail: gustviana@hotmail.com,gsa@uenf.br
\end{abstract}

\begin{abstract}
Polymorphism in the pattern of integument markings of Ceraeochrysa caligata (Neuroptera: Chrysopidae) larvae and adults and redescription of the larval instars. Ceraeochrysa caligata (Banks, 1945) is one of the several species of Ceraeochrysa Adams, 1982 that occur in agroecosystems of the Neotropical region and show potential for use in biological control programs. However, little is known about its biology, partly because of the poor status of the systematics of this group. To help in the identification of $C$. caligata and to contribute with additional characters for future phylogenetic studies with the genus, here we characterize the variations in relation to the pattern of integument markings originally described for the adults and larvae and redescribe the three larval instars, including characters not considered in the original description, especially the number of setae in the tubercles and somatic segments. We also present preliminary results regarding the nature of the variation in the pattern of adult markings.
\end{abstract}

KEY WORDS. Adult and larval polymorphism; biological control; green lacewing; morphology; systematics.

Ceraeochrysa Adams, 1982 é relativamente recente, tendo sido criado como parte do desmembramento de Chrysopa Leach, 1815, gênero amplo e reconhecidamente parafilético (ADAMs 1982). Com 54 espécies descritas, restritas ao Novo Mundo (Oswald 2007), Ceraeochrysa é um dos gêneros de Chrysopidae mais diversos deste continente. Sua distribuição estende-se do Canadá até a Argentina, mas a ampla maioria das espécies ocorre na Região Neotropical, onde são as mais comumente encontradas em diversos ecossistemas, como matas abertas e cultivos (pomares de frutíferas, milho e hortaliças) (TAUber et al. 2000, PEnNy 2002). Nestes cultivos, suas larvas se alimentam de vários artrópodes-pragas, como pulgões, moscas-brancas, ácaros e cochonilhas (Albuquerque et al. 2001, Freitas \& Penny 2001, Tauber \& DE LEÓN 2001). Esta característica, aliada à predisposição para a produção massal e à capacidade de se proteger de inimigos naturais, demonstra a potencialidade destes predadores como agentes de controle biológico de pragas (Albuquerque et al. 2001). Entretanto, o conhecimento da biologia está restrito a um pequeno número de espécies de Ceraeochrysa, em parte devido ao estado incipiente de sua sistemática. Essa situação começou a ser alterada com os estudos recentes de Penny $(1997,2002)$, TAuber et al. (2000), Freitas \& Penny (2001) e Tauber \& de León (2001).

Componente do grupo de espécies adaptadas a agroecossistemas e, portanto, candidata a agente de controle biológico, Ceraeochrysa caligata (Banks, 1945) ainda é totalmente desconhecida quanto à sua biologia. Esta espécie foi originalmente descrita como Chrysopa caligata, a partir de espécimes coletados no Panamá (BANKs 1945), sendo registrada posteriormente para o México (Banks 1948). Adams (1982) transferiu esta espécie para Ceraeochrysa, considerando-a sinônimo de Ceraeochrysa cincta (Schneider, 1851). O status de espécie válida foi restabelecido por AdAMs \& PENNY (1987), ao redescrevê-la com base no holótipo e espécimes adicionais do Panamá, além de numerosos espécimes por eles coletados no Brasil (Amazonas e Pará). Nesse estudo, esses autores apresentaram, pela primeira vez, descrições e ilustrações da genitália interna de machos e fêmeas. Em levantamentos recentes, Freitas \& Penny (2001) encontraram C. caligata em pomares de laranja no estado de São Paulo e em seringais no estado de Mato Grosso, enquanto Penny (2002) a encontrou na Costa Rica. Nos dois últimos trabalhos encontram-se não só descrições e ilustrações das genitálias, mas também da cabeça e tórax do adulto, que auxiliam sobremaneira na sua identificação.

Quase todas as descrições do estágio adulto de C. caligata mencionam manchas vermelho-escuras apenas no dorso do pedicelo e escapo da antena, que se estende até a fossa antenal, em forma de estreita faixa longitudinal central, e no dorso do protórax, em forma de faixa relativamente estreita ao longo de cada um de seus lados; todo o restante do corpo seria verde (BANKS 1945, Adams \& Penny 1987, Penny 2002). Apenas Freitas \& Penny (2001) mencionam, adicionalmente, um par de manchas vermelho-escuras no mesoescuto, sem destacá-las como diferença em relação à descrição original, mesmo tendo mencionado o 
exame do holótipo. Quanto aos estágios imaturos, TAUBER \& DE LEón (2001) descreveram com bom grau de detalhamento o ovo e os três instares larvais de C. caligata, obtidos a partir de espécimes coletados na América Central (Costa Rica e Belize).

Em coletas na região Norte Fluminense, estado do Rio de Janeiro, constatou-se a ocorrência de adultos de C. caligata com e sem manchas no mesoescuto. Durante sua criação em laboratório, verificaram-se também variações em relação ao padrão de manchas cefálicas dos instares larvais descritos por TAUBER \& DE LEÓN (2001). Em virtude destas variações morfológicas e da importância da caracterização correta dos estágios ativos para a identificação específica, neste trabalho é feita a redescrição dos instares larvais de C. caligata e a descrição do polimorfismo no padrão de manchas torácicas dos adultos. Na redescrição das larvas, incluiu-se o polimorfismo quanto às manchas cefálicas e ampliou-se o número de características consideradas, em especial a quetotaxia dos segmentos torácicos e abdominais, visando proporcionar maior número de caracteres para futuras análises filogenéticas. Além disso, ilustraram-se, pela primeira vez, os segmentos torácicos e abdominais do primeiro e terceiro instares. Quanto aos adultos, também se iniciou o estudo da natureza da variação polimórfica, por meio de um pequeno experimento de cruzamento em laboratório. Com estas informações, espera-se contribuir para a sistemática de Ceraeochrysa e incentivar novas investigações com estes agentes de controle biológico.

\section{MATERIAL E MÉTODOS}

Adultos de C. caligata foram coletados com rede entomológica em pomares mistos na Estação Experimental da PESAGRORIO $\left(21^{\circ} 44^{\prime} \mathrm{S}, 41^{\circ} 18^{\prime} \mathrm{W}\right)$ e no campus da Universidade Estadual do Norte Fluminense Darcy Ribeiro (UENF) $\left(21^{\circ} 45^{\prime} \mathrm{S}, 4^{\circ} 17^{\prime} \mathrm{W}\right)$, em Campos dos Goytacazes, Rio de Janeiro. No laboratório, foram colocados aos pares (um macho e uma fêmea) em gaiolas de criação contendo água destilada e dieta à base de levedo de cerveja, frutose e mel (1:1:1). Os ovos nelas depositados foram transferidos individualmente para tubos de vidro para obtenção e criação das larvas, que foram alimentadas com ovos de Anagasta kuehniella (Zeller, 1879) (Lepidoptera: Pyralidae). Três dias após a confecção do casulo, removeram-se os restos de alimento dos tubos e nestes foi inserida uma tira de papelão estreita para servir como substrato de fixação para a pupa móvel (adulto farado) realizar a muda e transformar-se em adulto. A criação de todos os estágios foi realizada em câmara climatizada do tipo BOD a $24 \pm 1^{\circ} \mathrm{C}$ e $14 \mathrm{hL}: 10 \mathrm{hE}$ de fotoperíodo. Exemplares de larvas e adultos de $C$. caligata provenientes dessa criação encontram-se depositados na Coleção Entomológica da UENF.

Três dias após a eclosão (primeiro instar) ou muda (segundo e terceiro instares), 10 espécimes de cada instar foram mortos em solução KAAD (BorRor et al. 1989), permanecendo nela imersos por 30 minutos, e depois preservados em álcool 95\%, para efetuar as descrições e medições e observar as variações nas características morfológicas. Posteriormente, cinco larvas de cada instar foram colocadas durante 24 horas em solução de $\mathrm{KOH}$ a $10 \%$ para clareamento, seguido de lavagem em $\mathrm{H}_{2} \mathrm{O}$ e imersão em solução de lignina rosa + fucsina para serem coradas, facilitando a observação das cerdas e dos escleritos.

A morfometria das larvas foi feita com ocular micrométrica acoplada ao microscópio estereoscópico Nikon SMZ800, com aumento de 20 vezes, para o comprimento do corpo das larvas de primeiro a terceiro instares, e de 136 (primeiro instar), 100 (segundo instar) e 80 vezes (terceiro instar) para o comprimento e largura da cápsula cefálica e o comprimento das mandíbulas. O comprimento do corpo foi medido do ápice das mandíbulas até a extremidade posterior do décimo segmento abdominal. O comprimento da cápsula cefálica foi medido medianamente, do cérvix ao clípeo, enquanto sua largura foi medida na altura da região ocular, incluindo os olhos. Como comprimento das mandíbulas, foi medida a distância linear entre o ápice e a base das mesmas.

As ilustrações das larvas foram realizadas com auxílio de câmara clara acoplada ao microscópio estereoscópico Nikon SMZ800 e as fotografias com auxílio de câmera fotográfica digital acoplada ao mesmo equipamento. Os caracteres usados na descrição dos três instares seguiram aqueles incluídos em TAuber et al. (2000) e TAUbER \& DE León (2001), com a adição das dimensões de algumas partes do corpo e do número de cerdas nos segmentos torácicos e abdominais e em seus tubérculos. A descrição da coloração das larvas foi feita com base em exemplares vivos e preservados.

Para iniciar as investigações sobre a natureza da variação no padrão de manchas no tórax dos adultos de C. caligata, foram obtidos 25 ovos de uma fêmea (+ macho) com a presença de mancha no mesoescuto e 25 ovos de uma fêmea (+ macho) com ausência desta mancha. Estes indivíduos foram acompanhados até a emergência dos adultos, para verificar o fenótipo da geração $\mathrm{F}_{1}$.

\section{RESULTADOS}

\section{Semaforonte B (segundo e terceiro instares)}

Características gerais (Fig. 1): 3,9 a 6,0 mm (segundo instar - L2) ou 6,4 a 7,8 mm (terceiro instar - L3) de comprimento total. Larva campodeiforme, gibosa, com tegumento branco a creme recoberto por espínulas da mesma cor. Espécimes vivos são predominantemente brancos, mas tendem a assumir cor creme quando preservados. Cerdas de três tipos (lisas pontiagudas, lisas com ponta em forma de gancho, serrilhadas pontiagudas) recobrindo o tegumento. Cabeça geralmente com apenas uma mancha (intermandibular) e cerda S12 ausente. Tubérculos relativamente curtos, mais largos na região apical. Protórax mais estreito do que demais segmentos torácicos. Escleritos torácicos praticamente despigmentados. Segmentos abdominais sem manchas dorsais ou ventrais, recobertos principalmente por cerdas lisas com ponta em forma de gancho. Presença de tubérculos abdominais laterais nos segmentos A2 a A8 e tubérculos látero-dorsais nos segmentos A1, A6 e A7. 

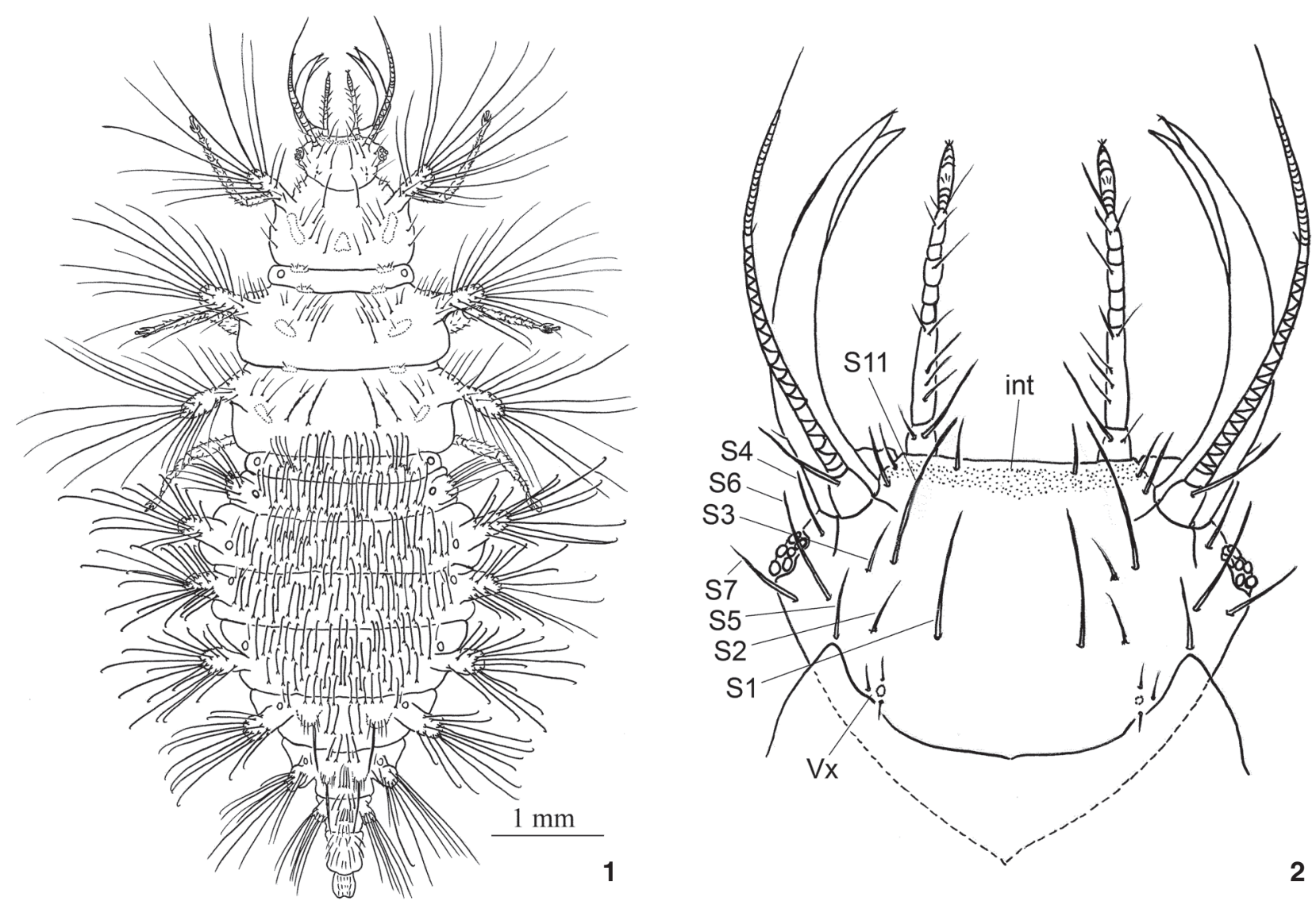

Figuras 1-2. Larva de terceiro instar de C. caligata: (1) vista dorsal; (2) cabeça, vista dorsal. (int) Mancha intermandibular, (Sx) cerda primária, $(\mathrm{V} x)$ três pequenas cerdas posteriores ao redor de um poro.

Cabeça (Figs 2-5): 0,47 a 0,64 mm (L2) ou 0,61 a 1,02 $\mathrm{mm}$ (L3) de comprimento e 0,88 a $0,95 \mathrm{~mm}$ (L2) ou 0,91 a 1,42 mm (L3) de largura; coloração branca a creme. Mandíbulas com comprimento variando de 0,59 a 0,85 (L2) ou de 0,78 a 0,95 mm (L3), âmbar-claras, com seis dentes apicais e uma cerda pequena na margem lateral externa, próximo à base. Extremidade apical da maxila com quatro cerdas pequenas. Palpos labiais com 12 cerdas lisas pontiagudas, de tamanho variável. Antena branca com uma cerda longa, lisa pontiaguda, no segmento basal, e uma cerda relativamente pequena na extremidade do segmento apical. Mancha intermandibular sempre presente, marrom-escura, contínua ou interrompida na região mediana (Fig. 3). Outras manchas cefálicas, de ocorrência ocasional, incluem um par de manchas látero-dorsais sinuosas, marrom-escuras, subcutâneas, entre a região posterior dos olhos e o cérvix (Fig. 4) e um par de manchas epicraniais, marromclaras (Fig. 5). Manchas frontais, pós-frontais e genais ausentes (estas últimas podem estar presentes no segundo instar). Cerdas primárias S1 a S11 presentes, lisas pontiagudas, sendo S1 e S11 de maior tamanho; cerda S12 ausente. Três cerdas Vx, menores que as cerdas primárias, na região posterior, próximo ao cérvix. Olhos constituídos por seis estemas pretos. Ausência de manchas na região ventral.

Tórax (Fig. 6): branco a creme, com escleritos praticamente despigmentados, pouco evidentes. Tubérculos laterais alongados, mais largos no ápice, sem manchas. Cerdas lisas pontiagudas e serrilhadas pontiagudas nos tubérculos e cerdas principalmente lisas pontiagudas nos segmentos. Pernas sem manchas, garras tarsais e empódio âmbar-claros.

Protórax: três cerdas pequenas (R1) na margem lateral anterior ao tubérculo. Tubérculos laterais alongados, projetados anteriormente, com cerdas apicais alongadas e subapicais pequenas, sobre as superfícies dorsal, lateral e ventral; em média, 10 (L2) ou 14 (L3) cerdas apicais e 6 (L2 e L3) subapicais, a maioria das apicais serrilhadas pontiagudas e todas subapicais lisas pontiagudas. Par de escleritos Sc1 pouco visíveis, despigmentados ou âmbar-claros, estendendo-se até a base do tubérculo, com uma cerda associada (S1Sc1); esclerito Sc2 pouco evidente, despigmentado ou âmbar-claro, de formato triangular. Ausência de escleritos secundários visíveis. Cerdas S1 a S5 

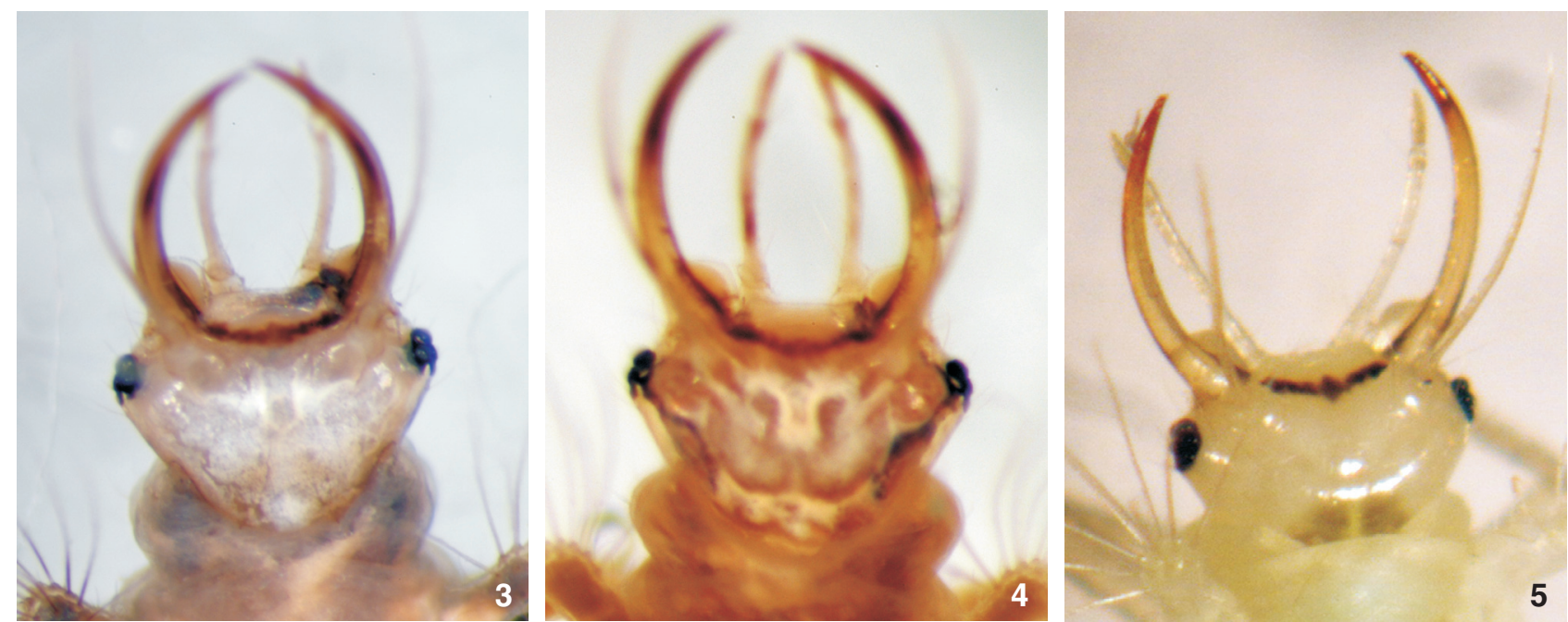

Figuras 3-5. Variações no padrão de manchas tegumentares em larvas de C. caligata : (3) cabeça do terceiro instar somente com mancha intermandibular; (4) cabeça do terceiro instar com mancha intermandibular e subcuticular dorso-lateral; (5) cabeça do segundo instar com mancha intermandibular e epicranial.

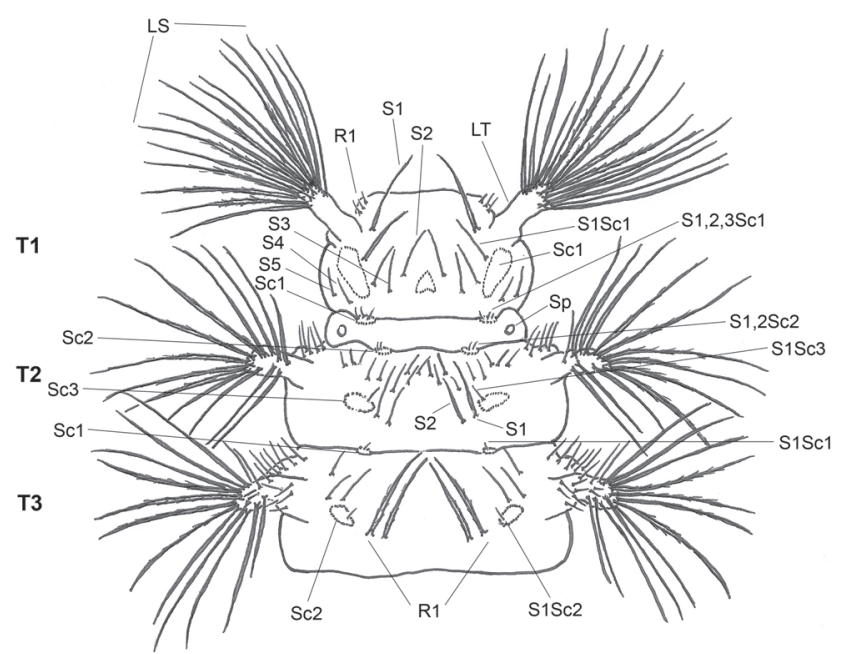

Figura 6. Tórax do terceiro instar de C. caligata, vista dorsal. (LS) Cerda no tubérculo lateral, (LT) tubérculo lateral, (R1) fileira de cerdas, (Scx) esclerito, (Sp) espiráculo, (Sx) cerda, (SxScx) cerda associada ao esclerito, (T1) protórax, (T2) mesotórax, (T3) metatórax.

lisas pontiagudas. Três pares de cerdas secundárias lisas pontiagudas entre Sc1 e Sc2.

Mesotórax: subsegmento anterior com aproximadamente 1/4 do comprimento do subsegmento posterior, com um par de espiráculos lateralmente e um par de escleritos Sc1 despigmentados, com três cerdas pequenas associadas. Subsegmento posterior com tubérculos laterais projetados lateralmente, cada um com 10 (L2) ou 11 (L3) cerdas apicais serrilhadas pontiagudas ou lisas pontiagudas e 6 (L2) ou 8 (L3) cerdas subapicais lisas pontiagudas. Um par de escleritos Sc2 despigmentados, com duas cerdas pequenas associadas, e um par de escleritos Sc3 ovalados, despigmentados, com uma cerda pequena associada; S1 e S2 lisas pontiagudas; 11 pares de cerdas pequenas entre Sc2 e Sc3.

Metatórax: tubérculos laterais projetados lateralmente, portando 8 (L2) ou 10 (L3) cerdas apicais serrilhadas pontiagudas ou lisas pontiagudas e 6 (L2) ou 8 (L3) cerdas subapicais lisas pontiagudas. Um par de escleritos Sc1 e Sc2 despigmentados, cada um com uma cerda pequena associada; fileira R1 formada por dois pares de cerdas longas, serrilhadas pontiagudas, partindo de chalazas sem manchas; cinco pares de cerdas curtas entre Sc1 e Sc2.

Abdome (Figs 7-9): giboso, variando de branco a creme, sem manchas no dorso e no ventre. Cerdas dorsais principalmente lisas com ponta em forma de gancho, exceto algumas nos tubérculos laterais e associadas aos espiráculos, lisas pontiagudas. Cerdas submedianas partindo de pequenas chalazas. Cerdas ventrais lisas pontiagudas. A1: mais curto do que demais segmentos; espiráculo com uma cerda pequena lisa pontiaguda associada; sem tubérculo lateral; tubérculo látero-dorsal com quatro cerdas lisas com ponta em forma de gancho; dois pares de cerdas S1 e S2 anteriormente e uma fileira de 18 cerdas submedianas, longas, com ponta em forma de gancho, partindo de pequenas chalazas, entre os tubérculos látero-dorsais. A2: tubérculo lateral sem manchas, com 8 (L2 e L3) cerdas apicais e 10 (L2 e L3) subapicais, lisas com ponta em forma de gancho. Tubérculo látero-dorsal ausente. Três fileiras de cerdas submedianas, longas, lisas com ponta em forma de gancho, partindo de chalazas, sendo 16 (L2) ou 24 (L3) na fileira anterior, 24 (L2 e L3) na intermediária e 24 (L2) ou 32 (L3) na posterior. Espiráculo com duas cerdas associadas, uma longa lisa com ponta em forma de gancho e uma curta lisa pontiaguda. A3-A5: tubérculo 

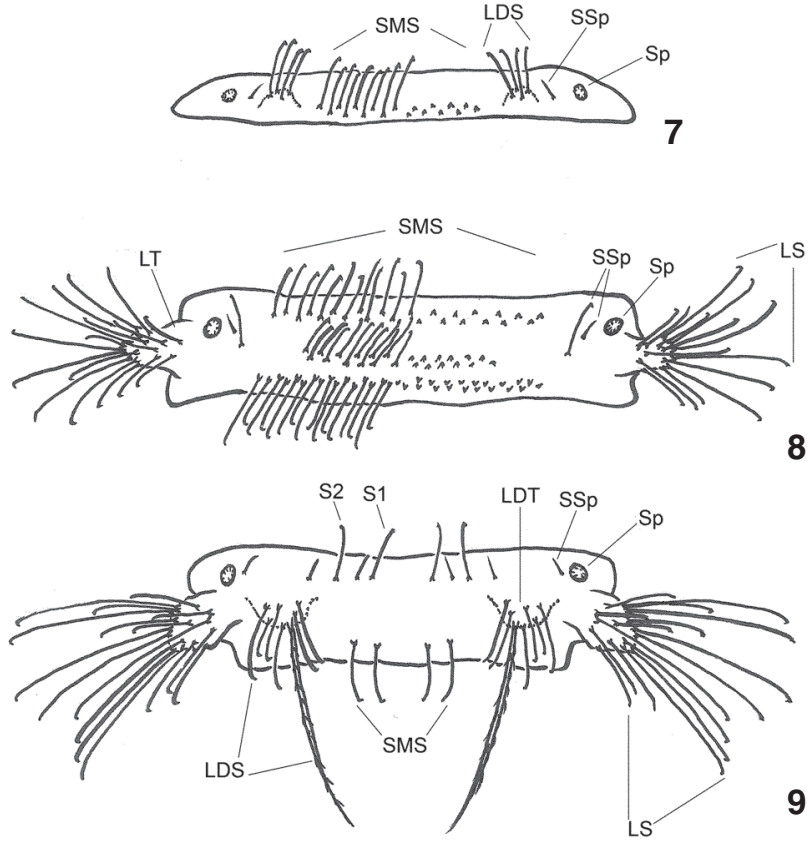

Figuras 7-9. Abdome do terceiro instar de C. caligata, vista dorsal: (7) primeiro segmento abdominal; (8) segundo segmento abdominal; (9) sexto segmento abdominal. (LDS) cerda no tubérculo látero-dorsal, (LDT) tubérculo látero-dorsal, (LS) cerda no tubérculo lateral, (LT) tubérculo lateral, (SMS) cerda submediana, (Sp) espiráculo, (SSp) cerda associada ao espiráculo, (Sx) cerda.

lateral sem manchas, com 10 (L2) ou 14 (L3) cerdas apicais longas e pontiagudas, lisas ou serrilhadas, e 8 (L2) ou 12 (L3) subapicais, lisas pontiagudas ou com ponta em forma de gancho. Tubérculo látero-dorsal ausente. Três fileiras de cerdas submedianas, longas, lisas com ponta em forma de gancho, sendo 12 (L2) ou 16 (L3) na anterior, 18 (L2) ou 12 (L3) na intermediária e 24 (L2) ou 32 (L3) na posterior. Espiráculo com duas cerdas associadas, uma lisa com ponta em forma de gancho e outra menor, lisa pontiaguda. A6: tubérculo lateral sem manchas, com 12 (L2) ou 16 (L3) cerdas apicais longas e pontiagudas, serrilhadas, e 4 (L2) ou 6 (L3) cerdas subapicais, lisas pontiagudas ou lisas com ponta em forma de gancho. Tubérculo láterodorsal sem manchas, com sete cerdas, seis lisas com ponta em forma de gancho e uma extremamente longa, serrilhada pontiaguda. Duas fileiras de cerdas submedianas, sendo a anterior formada por quatro pares, dois de cerdas maiores, lisas com ponta em forma de gancho ( $\mathrm{S} 1$ e S2), e dois de cerdas menores, lisas pontiagudas. Fileira posterior com dois pares de cerdas lisas com ponta em forma de gancho. Espiráculo com uma cerda pequena associada, lisa pontiaguda. A7: tubérculo lateral com 9 (L2) ou 10 (L3) cerdas apicais e 7 (L2) ou 15 (L3) cerdas subapicais, lisas pontiagudas ou lisas com ponta em forma de gancho em ambas posições. Tubérculo látero-dorsal sem manchas, com sete cerdas, seis lisas pontiagudas e uma extremamente longa, serrilhada pontiaguda. Dois pares de cerdas pequenas, lisas pontiagudas, na região anterior, e dois pares de cerdas pequenas, lisas pontiagudas, entre os tubérculos látero-dorsais. Espiráculo com uma cerda lisa pontiaguda associada. A8: tubérculo lateral, menor do que nos demais segmentos, com oito cerdas lisas pontiagudas. Tubérculo látero-dorsal ausente. Três grupos de cerdas pequenas, lisas pontiagudas: anterior com quatro, intermediário com seis e posterior com 12 cerdas. Espiráculo com uma cerda pequena, lisa pontiaguda, associada. A9: coberto dorsalmente por cerdas pequenas, lisas pontiagudas (aproximadamente nove pares maiores e 10 pares menores). Ausência de espiráculo e de tubérculos lateral e látero-dorsal. A10: coberto dorsalmente por cerdas pequenas, lisas pontiagudas (cerca de sete pares anteriormente e oito pares posteriormente), além de numerosas microcerdas na região distal do segmento.

\section{Semaforonte A (primeiro instar)}

Características gerais: 1,6 a 3,2 mm de comprimento total. Coloração branca. Mancha intermandibular distinguível, levemente pigmentada, na cabeça. Ausência de manchas nos segmentos torácicos e abdominais. Cerdas dos tubérculos longas.

Cabeça (Fig. 10): 0,22 a 0,26 mm de comprimento e 0,25 a $0,36 \mathrm{~mm}$ de largura. Branca com mancha intermandibular âmbar-clara. Demais manchas dorsais ausentes. Mancha genal geralmente presente. Mandíbulas com 0,23 a 0,32 mm de comprimento, âmbar-claras, com cinco dentes apicais. Maxilas com quatro microcerdas na extremidade apical. Palpos maxilares com quatro segmentos, com várias estriações no segmento distal e com três cerdas. Cerdas S1 a S11 presentes, lisas pontiagudas; S12 ausente. Três cerdas Vx curtas. Olhos pretos.

Tórax (Fig. 11): branco, com escleritos despigmentados. Cerdas serrilhadas pontiagudas nos tubérculos laterais e principalmente lisas pontiagudas nos segmentos. Pernas sem manchas, garras tarsais e empódio âmbar-claros.

Protórax: mais estreito do que os demais segmentos torácicos, com escleritos não pigmentados. Um par de escleritos Sc1 com uma cerda pequena associada. Tubérculos laterais projetados anteriormente com duas cerdas longas, serrilhadas pontiagudas. Cerda S1 longa e S2 a S5 curtas, lisas pontiagudas. Três cerdas R1 pequenas na margem lateral anterior ao tubérculo.

Mesotórax: subsegmento anterior bem curto, contendo um par de escleritos Sc1 despigmentados, com duas cerdas associadas, e um par de espiráculos lateralmente. Subsegmento posterior com dois pares de escleritos despigmentados, um na margem anterior (Sc2), com duas cerdas pequenas associadas, e outro na linha média (Sc3), com uma cerda pequena associada. Cerdas S1 e S2 lisas pontiagudas, sendo S1 mais curta do que S2. Tubérculos laterais com três cerdas longas, serrilhadas pontiagudas.

Metatórax: dois pares de escleritos (Sc1 e Sc2) despigmentados, ambos com uma cerda pequena, lisa pontiaguda, associada. R1 formada por duas cerdas bem longas, serrilhadas pontiagudas, entre os tubérculos laterais. Tubérculos laterais com três cerdas longas, serrilhadas pontiagudas. 


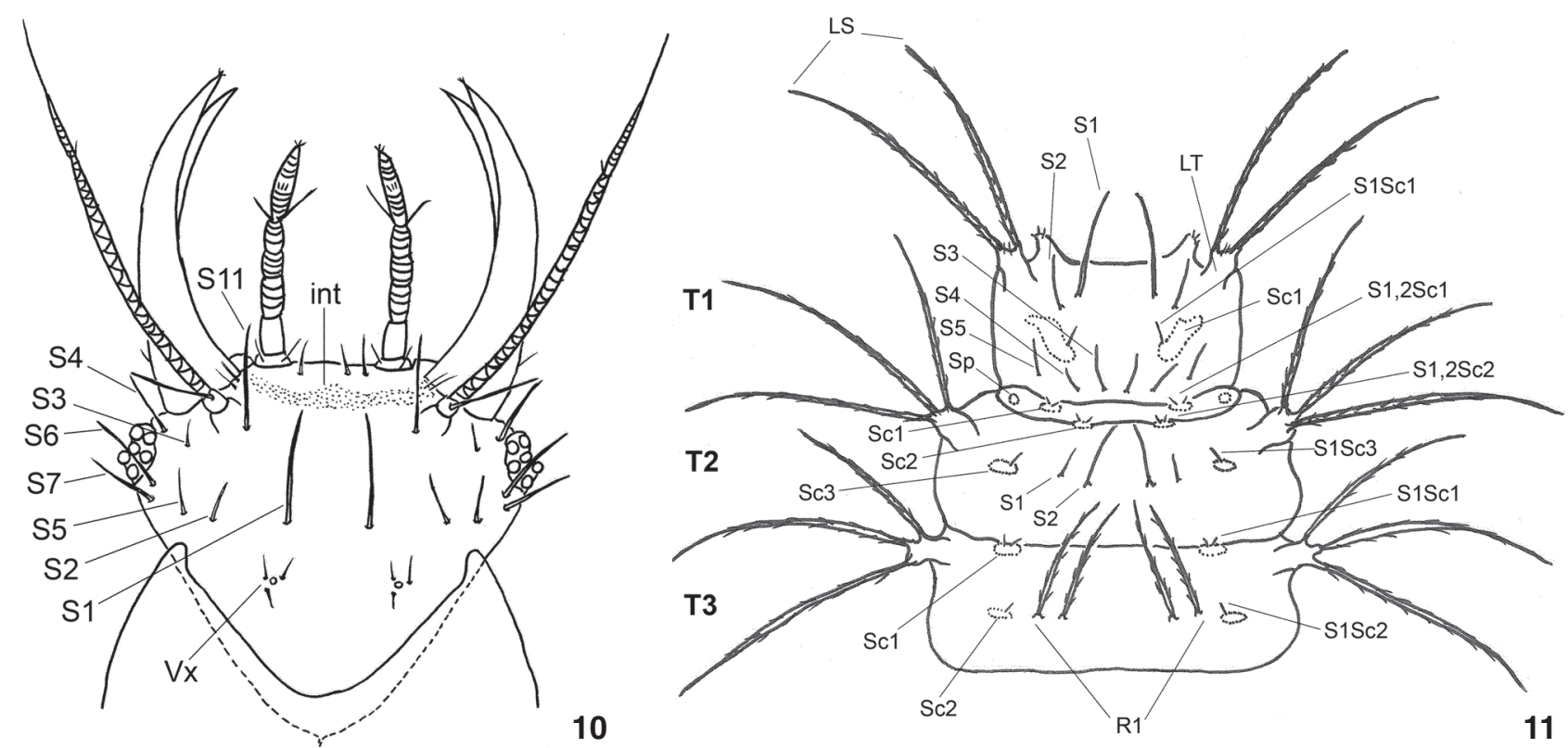

Figuras 10-11. Primeiro instar de C. caligata: (10) cabeça, vista dorsal; (11) tórax, vista dorsal. (int) Mancha intermandibular, (Sx) cerda primária, $(V x)$ três pequenas cerdas posteriores ao redor de um poro, (LS) cerda no tubérculo lateral, (LT) tubérculo lateral, (R1) fileira de cerdas, ( $\mathrm{Scx}$ ) esclerito, (Sp) espiráculo, ( $\mathrm{S} x \mathrm{Scx}$ ) cerda associada ao esclerito, (T1) protórax, (T2) mesotórax, (T3) metatórax.

Abdome (Fig. 12): não giboso, branco, sem manchas no dorso e no ventre. Cerdas dorsais lisas pontiagudas ou com ponta em forma de gancho. Cerdas submedianas partindo de pequenas chalazas. A1: mais curto do que os demais; tubérculo lateral ausente, tubérculo látero-dorsal com duas cerdas lisas com ponta em forma de gancho. Uma fileira de seis cerdas submedianas longas, lisas pontiagudas, partindo de chalazas, entre os tubérculos látero-dorsais, e duas cerdas menores (S1 e S2) posicionadas anteriormente às submedianas. Espiráculos com uma cerda longa com ponta em forma de gancho associada. A2-A5: tubérculos laterais com duas cerdas longas, serrilhadas pontiagudas (em A2 e A3, uma dessas cerdas é lisa com ponta em forma de gancho). Tubérculos látero-dorsais com duas cerdas longas, lisas com ponta em forma de gancho. Uma fileira de seis cerdas submedianas longas, lisas com ponta em forma de gancho, posicionadas de forma alternada, entre os tubérculos látero-dorsais. Espiráculos com uma cerda longa, lisa com ponta em forma de gancho, associada.

A6-A7: tubérculos laterais com duas cerdas longas, serrilhadas pontiagudas. Tubérculo látero-dorsal com duas cerdas, uma pequena, lisa pontiaguda, e outra longa, serrilhada pontiaguda. Adicionalmente, quatro cerdas lisas com ponta em forma de gancho, duas anteriormente posicionadas (S1 e S2) e duas submedianas, entre os tubérculos látero-dorsais. Espiráculos pequenos sem cerdas associadas. A8: tubérculo lateral pouco projetado, com duas cerdas curtas, lisas pontiagudas. Quatro cerdas pequenas, lisas pontiagudas, na superfície dorsal. Espiráculo com uma cerda pequena, lisa pontiaguda,

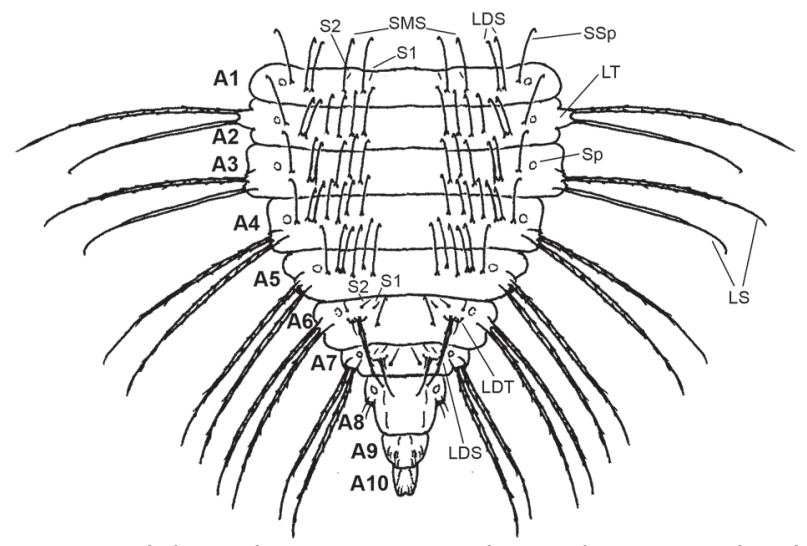

Figura 12. Abdome do primeiro instar de C. caligata, vista dorsal. (A1-A10) Primeiro ao $10^{\circ}$ segmentos abdominais, (LDS) cerda no tubérculo látero-dorsal, (LDT) tubérculo látero-dorsal, (LS) cerda no tubérculo lateral, (LT) tubérculo lateral, (SMS) cerda submediana, (Sp) espiráculo, (SSp) cerda associada ao espiráculo, (Sx) cerda.

associada. A9: quatro a seis cerdas pequenas, lisas pontiagudas, na superfície dorsal. A10: mais curto e estreito do que os demais segmentos, com cerca de 12 microcerdas.

\section{DISCUSSÃO}

\section{Polimorfismo no padrão de manchas das larvas}

A maior parte das características das larvas de C. caligata descritas por TAuber \& De León (2001), com base em espécimes 
originários da América Central (Belize e Costa Rica), foram observadas nas larvas oriundas do norte do estado do Rio de Janeiro. A grande diferença foi relacionada ao padrão de manchas cefálicas. Enquanto na descrição de TAUBER \& DE LEón (2001) é mencionada a presença apenas da mancha intermandibular, contínua, em todos os instares, além da mancha genal no primeiro instar, neste trabalho foram observadas as seguintes variações: (1) mancha intermandibular, nos três instares, contínua ou interrompida no centro, sendo esta característica observada tanto nas larvas in vivo quanto nas larvas preservadas; (2) presença ou ausência de um par de manchas epicraniais marrom-claras, mais evidentes no segundo instar, mas perceptíveis também no terceiro instar; (3) presença ou ausência de um par de manchas dorso-laterais subcutâneas, entre a margem posterior dos olhos e o cérvix, no terceiro instar. Além desta, muito poucas diferenças foram encontradas, como o número de cerdas associadas aos espiráculos (1 vs. 2) nos segmentos A6 e A7 do terceiro instar. Isto demonstra a grande estabilidade dos caracteres morfológicos das larvas de C. caligata, pois as populações aqui comparadas são oriundas de regiões geográficas distantes (separadas por mais de $5.000 \mathrm{~km}$ ).

Poucos estudos registram a existência de variações intraespecíficas no padrão de manchas cefálicas de larvas de Chrysopidae, e todos eles envolvem espécies crípticas do grupo carnea de Chrysoperla Steinmann, 1964 (Henry et al. 1996, 1999, 2002). Nesses estudos, foram encontradas variações na forma e no número de manchas cefálicas das larvas de Chrysoperla lucasina (Lacroix, 1912), C. mediterranea (Hölzel, 1972), C. carnea s. str. (Stephens, 1836) e C. pallida (Henry et al., 2002). Como no estágio adulto, as larvas dessas espécies são extremamente semelhantes; sua identificação precisa só é possível pela análise dos sons vibracionais produzidos com seu abdome durante o comportamento de corte. Nessas espécies, as variações no padrão de manchas cefálicas encontradas entre populações de regiões geográficas distantes na Europa e dentro destas populações foram da mesma magnitude, o que levou Henry et al. (2001) a concluírem que não há diferenças consistentes que permitam a separação das mesmas. Em C. caligata este problema não existe, pois ela é facilmente distinguível das demais espécies de Ceraeochrysa pela morfologia dos adultos (principalmente da genitália) e das larvas (Adams \& Penny 1987, Tauber et al. 2000, Freitas \& Penny 2001, TAUber \& DE LEÓN 2001). Mesmo o polimorfismo de coloração aqui descrito não se sobrepõe aos padrões de manchas cefálicas das larvas de outras espécies de Ceraeochrysa já descritas, de forma que esta informação vem somente contribuir para a correta identificação de C. caligata.

\section{Polimorfismo no padrão de manchas dos adultos}

Conforme já descrito acima, foi constatada na região Norte Fluminense do estado do Rio de Janeiro a existência de polimorfismo no padrão de manchas do estágio adulto de $C$. caligata, tanto em fêmeas como em machos. Além da faixa vermelho-escura estreita longitudinal centro-dorsal do pedicelo e escapo das antenas e das faixas laterais vermelho-escuras no dorso do protórax, sempre presentes, foram coletados espécimes com um par de manchas arredondadas vermelho-escuras no mesoescuto do mesotórax (Fig. 13). Embora não quantificada, sua freqüência nas coletas de campo foi inferior em relação aos espécimes sem estas manchas (Fig. 14).
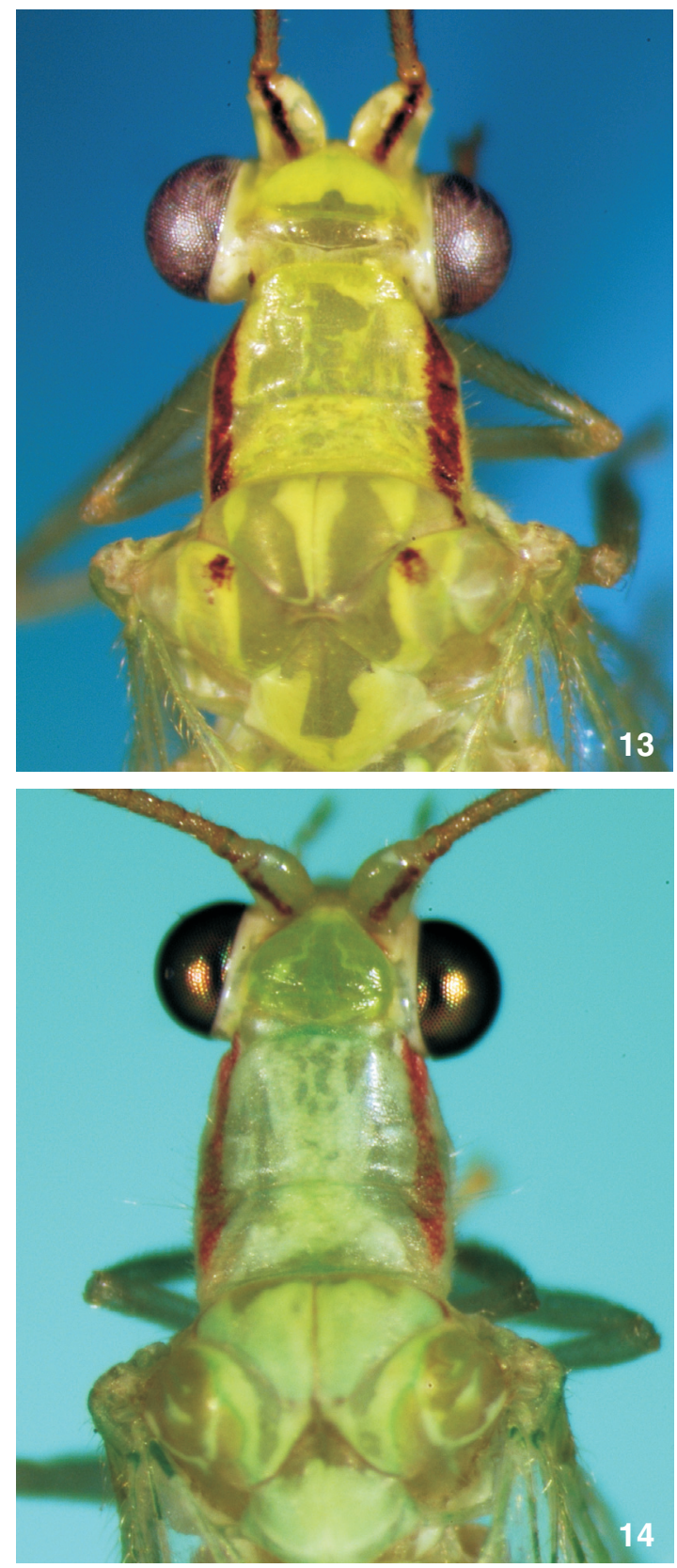

Figuras 13-14. Variações no padrão de manchas tegumentares de fêmeas e machos de C. caligata: (13) adulto com manchas vermeIho-escuras no mesoescuto; (14) adulto sem manchas no mesoescuto. 
Na criação de laboratório, 85,7\% dos descendentes do casal com manchas no mesotórax apresentou o fenótipo com manchas, enquanto 90,5\% dos descendentes do casal sem manchas apresentou o fenótipo sem manchas; somente dois indivíduos apresentaram fenótipo distinto do fenótipo dos pais em ambos os casos (Fig. 15). Portanto, os dois fenótipos foram expressos na geração $\mathrm{F}_{1}$. Estes resultados demonstram claramente que o polimorfismo no padrão de manchas se trata de uma variação intra-específica intrapopulacional de C. caligata. Por outro lado, como os dois casais foram oriundos do campo, não é possível assegurar a paternidade da geração $\mathrm{F}_{1}$ e, conseqüentemente, definir a natureza (se estritamente genética, mais provável, ou se sofre alguma influência do ambiente) e modo de herança (se existe dominância de algum alelo) deste polimorfismo, o que só será possível com experimentos especialmente delineados para este fim.

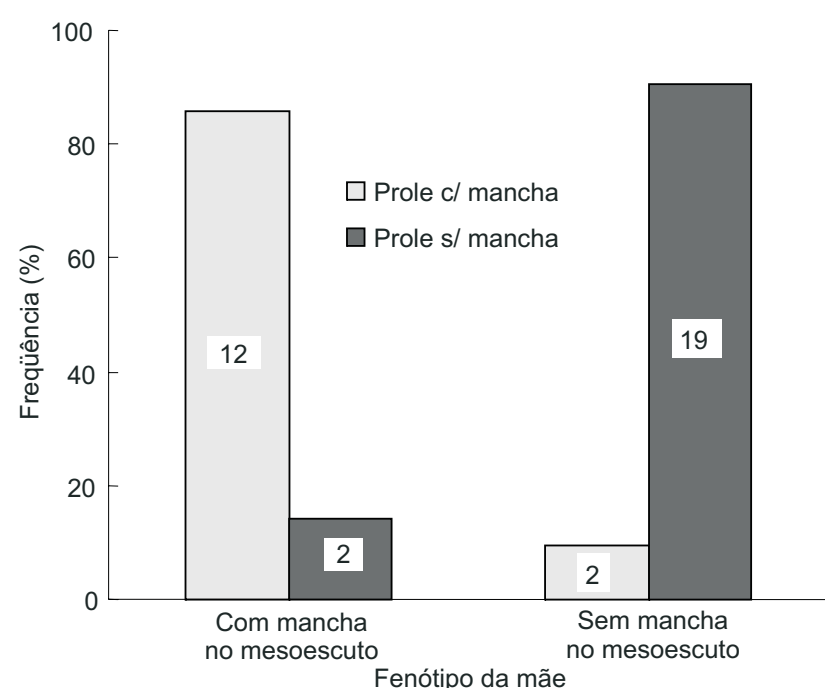

Figura 15. Relação entre o fenótipo das fêmeas de C. caligata coletadas no campo e o fenótipo da geração $F_{1}$ obtida em laboratório. Número de indivíduos indicado nas barras.

Variações intra-específicas nos padrões de manchas tegumentares de adultos de Chrysopidae, como as aqui descritas para C. caligata, já haviam sido reportadas na literatura. É o caso de Leucochrysa (Leucochrysa) varia (Schneider, 1851), que apresenta quatro fenótipos em relação à coloração dos escleritos do meso e metanoto (MANTOANelli et al. 2006). Em Ceraeochrysa, estas variações foram descritas para várias espécies, como C. cincta (cor da antena, forma e número de manchas no escapo e no pronoto), C. claveri (Navás, 1911) (número de manchas no escapo, cor da antena) e C. lineaticornis (Fitch, 1855) (mancha no pronoto) (Adams \& Penny 1987, Tauber et al. 2000). Enquanto para $L$. (L.) varia a variação intrapopulacional foi demonstrada e sua natureza foi discutida com base em cruzamentos, para
Ceraeochrysa spp. foi sugerido que estas variações seriam interpopulacionais, ou seja, estariam associadas com diferentes regiões geográficas. Esta é a primeira vez que se demonstra experimentalmente a ocorrência de polimorfismo intrapopulacional no padrão de manchas tegumentares de adultos de Ceraeochrysa.

\section{AGRADECIMENTOS}

A Jatinder S. Multani, pelo auxílio nas coletas de campo e criação em laboratório. A Catherine A. Tauber (Cornell University, EUA) e Norman D. Penny (California Academy of Sciences, EUA), pela confirmação da identidade de Ceraeochrysa caligata. Ao $\mathrm{CNPq}$, pela bolsa de produtividade em pesquisa (Processos 300504/96-9 e 303287/2005-5) e auxílio financeiro (Processos 466439/00-8 e 475848/2004-7) concedidos ao segundo autor.

\section{LITERATURA CITADA}

Adams, P.A. 1982. Ceraeochrysa, a new genus of Chrysopinae (Neuroptera) (Studies in New World Chrysopidae, Part II). Neuroptera International 2 (2): 69-75.

Adams, P.A. \& N.D. Penny. 1987. Neuroptera of the Amazon Basin. Part 11a. Introduction and Chrysopini. Acta Amazonica 15 (3-4): 413-479.

Albuquerque, G.S.; C.A. Tauber \& M.J. Tauber. 2001. Chrysoperla externa and Ceraeochrysa spp.: potential for biological control in the New World tropics and subtropics, p. 408-423. In: P.K. McEwen; T.R. New \& A.E. WhitTington (Eds). Lacewings in the crop environment. Cambridge, Cambridge University Press, XVIII+546p.

BAnks, N. 1945. A review of the Chrysopidae (Nothochrysidae) of Central America. Psyche 52 (3-4): 139-174.

BANKs, N. 1948. Chrysopidae (Nothochrysidae) collected in Mexico by Dr. A. Dampf (Neuroptera). Psyche 55 (4): 151177.

Borror, D.J.; C.A. Triplehorn \& N.F. Johnson. 1989. An introduction to the study of insects. Philadelphia, Saunders, $6^{\text {th }}$ ed., $875 \mathrm{p}$.

Freitas, S. \& N.D. Penny. 2001. The green lacewings (Neuroptera: Chrysopidae) of Brazilian agro-ecosystems. Proceedings of the California Academy of Sciences 52 (19): 245-395.

Henry, C.S.; S.J. Brooks; J.B. Johnson \& P. Duelli. 1996. Chrysoperla lucasina (Lacroix): a distinct species of green lacewing, confirmed by acoustical analysis (Neuroptera: Chrysopidae). Systematic Entomology 21: 205-218.

Henry, C.S.; S.J. Brooks; J.B. Johnson \& P. Duelu. 1999. Revised concept of Chrysoperla mediterranea (Hölzel), a green lacewing associated with conifers: courtship songs across 2800 kilometers of Europe (Neuroptera: Chrysopidae). Systematic Entomology 24: 335-350.

Henry, C.S.; S.J. Brooks; D. Thierry; P. Duelli \& J.B. Johnson. 2001. The common green lacewing (Chrysoperla carnea s. lat.) and the sibling species problem, p. 29-42. In: P.K. McEwen; T.R. New \& A.E. WhitTington (Eds). Lacewings in the crop envi- 
ronment. Cambridge, Cambridge University Press, XVIII+ $546 \mathrm{p}$.

Henry, C.S.; S.J. Brooks; P. Duelli \& J.B. Johnson. 2002. Discovering the true Chrysoperla carnea (Insecta: Neuroptera: Chrysopidae) using song analysis, morphology, and ecology. Annals of the Entomological Society of America 95 (2): 172-191.

Mantoanelli, E.; G.S. Albuquerque; C.A. Tauber \& M.J. Tauber. 2006. Leucochrysa (Leucochrysa) varia (Schneider) (Neuroptera: Chrysopidae): larval descriptions, developmental rates, and adult color variation. Annals of the Entomological Society of America 99 (1): 7-18.

Oswald, J.D. 2007. Ceraeochrysa. Neuropterida species of the world, version 2.0. 54 registros de espécies válidas. Disponível na World Wide Web em: http://lacewing.tamu.edu/ Species-Catalogue/ [30/04/2008].
Penny, N.D. 1997. Four new species of Costa Rican Ceraeochrysa (Neuroptera: Chrysopidae). Pan-Pacific Entomologist 73 (2): 61-69.

Penny, N.D. 2002. A guide to the lacewings (Neuroptera) of Costa Rica. Proceedings of the California Academy of Sciences 53 (12): 161-457.

Tauber, C.A. \& T. De León. 2001. Systematics of green lacewings (Neuroptera: Chrysopidae): larvae of Ceraeochrysa from Mexico. Annals of the Entomological Society of America 94 (2): 197-209.

Tauber, C.A.; T. De León; N.D. Penny \& M.J. Tauber. 2000. The genus Ceraeochrysa (Neuroptera: Chrysopidae) of America North of Mexico: larvae, adults and comparative biology. Annals of the Entomological Society of America 93 (6): 1196-1221.

Submitted: 25.VI.2008; Accepted: 09.III.2009.

Editorial responsibility: Gabriel Mejdalani 